\title{
Reliability of the weight-bearing ankle dorsiflexion range of motion measurement using a smartphone goniometer application
}

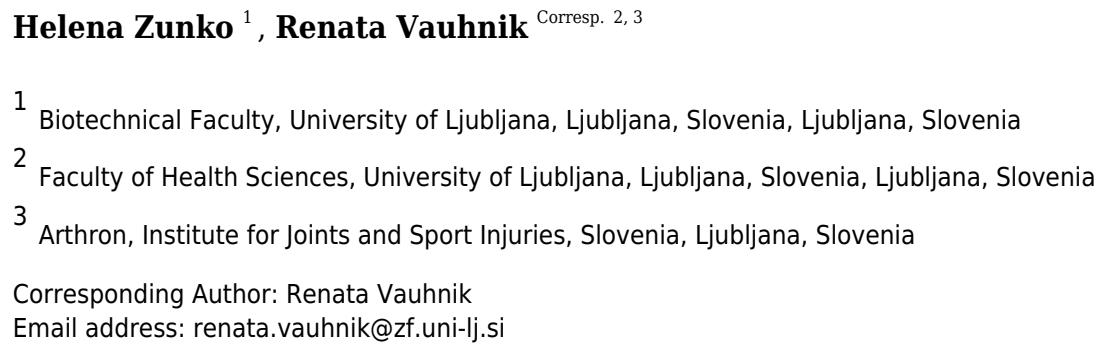

Background: Weight-bearing ankle dorsiflexion range of motion measurement (weightbearing lunge test) is gaining in popularity because it mimics lower extremity function in daily physical activities. The purpose of the study is to assess the intra-rater and the interrater reliability of the weight-bearing ankle dorsiflexion range of motion measurement with a flexed knee using a smartphone application Spirit Level Plus installed on an Android smartphone. Methods: 32 young, healthy subjects participated in the study and were measured in four sessions by two examiners. One measurement was taken on each ankle in every session. Eight measurements were taken from each participant. A total of 256 were taken from all the participants. The measurements for the individual subject were repeated no sooner than 24 hours after the first session. In order to assess the reliability, intraclass correlation coefficients (ICC), standard error measurements (SEM) and minimal detectable change (MDC) at the $95 \%$ confidence interval were calculated. Results: Statistical data analysis revealed moderate intra-rater reliability for the right ankle (ICC $=$ $0.72,95 \% \mathrm{Cl}: 0.49-0.85$ ) and good intra-rater reliability for the left ankle (ICC $=0.82,95 \%$ $\mathrm{Cl}: 0.66-0.91)$. Inter-rater reliability is moderate for the right (ICC $=0.73,95 \% \mathrm{Cl}$ : $0.52-0.86)$ and the left ankle (ICC $=0.65,95 \% \mathrm{Cl}: 0.39-0.81)$. Conclusion: The observed method is moderately reliable and appropriate when the main objective is to assess ankle dorsiflexion mobility in weight-bearing when weight-bearing is not contraindicated. The concurrent validity of the Spirit Level Plus application is excellent. 


\title{
2 Reliability of the weight-bearing ankle dorsiflexion
}

3 range of motion measurement using a smartphone

4 goniometer application.

5

6

7

8

9

10

\author{
Helena Zunko ${ }^{1}$, Renata Vauhnik ${ }^{2,3}$ \\ ${ }^{1}$ Biotechnical Faculty, University of Ljubljana, Ljubljana, Slovenia \\ ${ }^{2}$ Faculty of Health Sciences, University of Ljubljana, Ljubljana, Slovenia \\ ${ }^{3}$ Arthron, Institute for Joint and Sports Injuries, Ljubljana, Slovenia
}

Corresponding Author:

Renata Vauhnik

Zdravstvena pot 5, 1000 Ljubljana, Slovenia

Email address: renata.vauhnik@zf.uni-lj.si

\section{Abstract}

Background: Weight-bearing ankle dorsiflexion range of motion measurement (weight-bearing lunge test) is gaining in popularity because it mimics lower extremity function in daily physical activities. The purpose of the study is to assess the intra-rater and the inter-rater reliability of the weight-bearing ankle dorsiflexion range of motion measurement with a flexed knee using a smartphone application Spirit Level Plus installed on an Android smartphone.

Methods: 32 young, healthy subjects participated in the study and were measured in four sessions by two examiners. One measurement was taken on each ankle in every session. Eight measurements were taken from each participant. A total of 256 were taken from all the participants. The measurements for the individual subject were repeated no sooner than 24 hours after the first session. In order to assess the reliability, intraclass correlation coefficients (ICC), standard error measurements (SEM) and minimal detectable change (MDC) at the $95 \%$ confidence interval were calculated.

Results: Statistical data analysis revealed moderate intra-rater reliability for the right ankle (ICC $=0.72,95 \%$ CI: $0.49-0.85)$ and good intra-rater reliability for the left ankle $(\mathrm{ICC}=0.82,95 \% \mathrm{CI}$ : $0.66-0.91)$. Inter-rater reliability is moderate for the right ( $\mathrm{ICC}=0.73,95 \% \mathrm{CI}: 0.52-0.86)$ and the left ankle (ICC $=0.65,95 \%$ CI: 0.39-0.81).

Conclusion: The observed method is moderately reliable and appropriate when the main objective is to assess ankle dorsiflexion mobility in weight-bearing when weight-bearing is not contraindicated. The concurrent validity of the Spirit Level Plus application is excellent. 
40

41

42

43

44

45

46

47

48

49

50

51

52

53

54

55

56

57

58

59

60

61

62

63

64

65

66

67

68

69

70

71

72

73

74

75

76

77

78

\section{Introduction}

Adequate ankle dorsiflexion range of motion (ankle dorsiflexion ROM) is necessary for performing daily physical activities like walking, rising from the sitting position, running and stair climbing (Bohannon, Tiberio \& Zito, 1997; Kluding \& Santos, 2008; Konor et al., 2012; Rabin et al., 2015). Therefore, inadequate ankle dorsiflexion ROM directly affects individual's functioning, but also represents a risk factor for lower limb injuries (Munteanu et al., 2009), falls in the elderly (Gehlsen \& Whaley, 1990) and development of other pathologies due to altered biomechanics and compensatory movement patterns (Dinh et al., 2011).

There is a wide variety of common causes of reduced ankle dorsiflexion ROM . The range may be reduced due to lower limb injuries such as ankle sprain (Garrick \& Requa, 1988), the presence of other pathological conditions such as Achilles tendinopathy (Duthon et al., 2011), plantar fasciopathy (Cheung, Zhang \& An, 2006), arthrosis (Barg et al., 2013), diabetes (Searle MOsteo, Spink \& Chuter, 2018), post-stroke conditions (Chung et al., 2004), prolonged immobility (Akeson et al., 1987) and age-related changes in the mechanical properties of muscles and soft tissues (Gajdosik, Vander Linden \& Williams, 1999).

Increasing ankle dorsiflexion ROM is a common physiotherapeutic goal. Current evidence of the effectiveness of therapeutic procedures is limited mainly by the absence of a uniform definition of physiological normative ankle dorsiflexion ROM values and differences in measurement procedures (Charles, Scutter \& Buckley, 2010; Young et al., 2013). Valid, reliable, and accurate goniometric measurements are required in order to assess the effectiveness of therapeutic procedures and further treatment planning (Jones et al., 2005; Wilken et al., 2011). Weightbearing measurement is gaining popularity and is more suitable for function assessment than non weight-bearing ankle dorsiflexion ROM measurement procedures (Powden, Hoch \& Hoch, 2015; Zunko \& Puh, 2016). The procedure mimics a functional position of the lower limb during daily physical activities, hence the term functional measurement has been proposed by some authors (Jones et al., 2005; Krause et al., 2011; Dickson et al., 2012; Rabin \& Kozol, 2012).

Several different measurement procedures have been developed using different measurement tools. The most commonly used measurement tools are different types of goniometers and tape measure. Some authors used special devices (Jones et al., 2005; Watson, Boland \& Refshauge, 2008; Morales et al., 2016; Munteanu et al., 2009) or mobile applications of goniometers (Banwell et al., 2019; Goose et al., 2021; Williams, Caserta \& Haines, 2013; Vohralik et al., 2015).

In medicine, there is a growing trend of using various mobile applications on smartphones instead of standard measuring tools because of their accessibility, affordability and simplicity (Franko \& Tirrell, 2012). Williams et al. (2013), who measured ankle dorsiflexion ROM in 
80

81

82

83

84

85

86

87

88

89

90

91

92

93

94

95

96

97

98

99

100

101

102

103

104

105

106

107

108

109

110

111

112

113

114

115

116

117

118

weight-bearing, using a mobile goniometer application TiltMeter App, installed on a smartphone (IOS operating system), reported that the measurement intra-rater and inter-rater reliability at the extended knee and flexed knee is excellent (ICC 0.8 or more). Two other studies (Gosse at al., 2021; Banwell et al., 2019), investigating the use of Apple IOS based goniometer applications for weight-bearing ankle dorsiflexion ROM measurement, determined moderate to excellent reliability and excellent validity.

Although there are several studies, reporting the reliability of the weight-bearing ankle dorsiflexion ROM measurement using Apple IOS based goniometer applications, evidence of the reliability of a mobile goniometer application using an Android smart phone for weight-bearing ankle dorsiflexion ROM measurement is limited. Therefore, the aim of our study was to determine inter-rater and intra-rater reliability of the weight-bearing ankle dorsiflexion ROM measurement with the flexed knee, using a mobile goniometer application Spirit Level Plus installed on an Android smartphone.

\section{Materials \& Methods}

This study followed a test-retest design to determine intra-rater and inter-rater reliability of the weight-bearing ankle dorsiflexion ROM measured by an experienced physiotherapist and a physiotherapy student. The concurrent validity for the Spirit Level Plus application was established when compared to the universal goniometer at angle 0 and 45 degrees.

The study was approved by the Republic of Slovenia National Medical Ethics Committee (No. 0120-235/2017/5).

\section{Participants}

The inclusion criteria for participation in the study was absence of musculoskeletal injuries in the lower limbs or other disorders of the neuromuscular system, including inflammatory joint conditions, in the last six months prior to the measurements. 32 young, healthy participants (23 women $(72 \%)$ and 9 men $(28 \%)$, age $20.9 \pm 1.7$ years, body height $170.7 \pm 8.1 \mathrm{~cm}$, body mass $66.2 \pm 11.6 \mathrm{~kg}$ ), who signed an informed consent, participated in the study. Research recruitment leaflets were used for participants recruitment. Descriptive statistics of the participants are presented in Table 1.

\section{Examiners}

The measurements were conducted by a physiotherapist with 16 years of clinical experience in the field of musculoskeletal physiotherapy, who has been using this measurement procedure regularly, and a final year physiotherapy student, who has been instructed how to perform the measurements prior to the study. Prior to the main data collection, the pilot study was conducted to refine the protocol. Both examiners are right-handed.

\section{Measurement of the weight-bearing ankle dorsiflexion ROM}


119 The measurement procedure was demonstrated to all participants on one on one. The first one to

120

121

122

123

124

125

126

127

128

129

130

131

132

133

134

135

136

137

138

139

140

141

142

143

144

145

146

147

148

149

150

151

152

153

154

155

156

157

158

conduct the measurements was an experienced physiotherapist, followed by the physiotherapy student. At least 24 hours elapsed between measurements in each participant. Eight measurements were taken from each participant. A total of 256 were taken from all the participants. Examiners performed the first and the second measurements on different days, therefore the stretch from the first measurement could not influence the result of the second measurement. Left and right ankle dorsiflexion ROM were measured, the left ankle dorsiflexion ROM was measured from the participant's left side, and the right ankle dorsiflexion ROM from the right side. Due to a rather large sample size, and the fact that both sides were being measured, it was impossible for the examiners to memorise the results. The measurements were collected on paper separately, so the examiners were blinded to each other's measurements.

The participants were requested to stand in front of the wall and they were allowed to use the wall for support if needed. They were then asked to take one step back with the leg that was measured and place the foot parallel to the other in the direction perpendicular to the wall. The next instruction was to move the knee forward toward the wall, aligned over the second toe, and stop just before the heel starts lifting off the ground. At this point the measurements were taken by placing the short side of the smartphone (Huawei P8lite) on the posterior part of the Achilles tendon, one centimetre above the posterior calcaneal tuberosity, and using the mobile goniometer application Spirit Level Plus to measure the tibia inclination relative to the floor (Fig. 1). The application Spirit Level Plus (now named Spirit Level) was developed by Keuwlsoft (www.Keuwl.com). The application is free to download, no subscription is needed. Android 1.6+ operating system is required. Prior to the measurement, the smartphone was placed with its long axis on the floor and calibrated to $0^{\circ}$. Similar procedure has been used by other researchers (Bennell et al., 1999; Burns \& Crosbie, 2005; Rose, Burns \& North, 2010; Williams, Caserta \& Haines, 2013, Banwell et al., 2019; Goose et al., 2021).

The examiners were supervising the movement of the heel and the knee by holding the heel and guiding the movement of the knee while the subject moved it forward towards the wall. If the heel started to lift, the procedure was stopped and repeated. All the measurements were performed while the subjects were barefoot.

\section{Statistical procedure}

Reliability of measurements was assessed by intraclass correlation coefficients (ICC) and standard errors of measurement (SEM) from which minimum detectable change (MDC) was determined. ICC $(2,1)$ was used to calculate (a) intra-rater as well as (b) inter-rater reliability. The degree of reliability of the test, measured by ICC, was determined according to the classification of Portney and Watkins (2009) (value between 0.00-0.49 denotes poor, 0.50-0.79 moderate and 0.80-1 good reliability). Concurrent validity of the application was explored using ICCs (Model 3,1) (Two-way mixed effect with absolute agreement). The R statistical program

Peer) reviewing PDF | (2021:03:58796:2:0:CHECK 19 Jul 2021) 
159 (R Core Team, 2013) was used to analyse the data. Level of statistical significance was set to 160 alpha $=0.05$.

161

162

\section{Results}

163

164

165

166

167

168

169

170

171

172

173

174

175

176

177

178

179

180

181

182

183

184

185

186

187

188

189

190

191

192

193

194

195

196

197

198

Ankle dorsiflexion ROM measurements are presented in Table 2.

Intra-rater reliability was good (and at least moderate in considering confidence interval) for the left leg (ICC $=0.82,95 \%$ CI: $0.66-0.91)$ and moderate for the right leg (ICC $=0.72,95 \%$ CI: $0.49-0.85)$. SEM was less than 1.9 degrees. Minimum detectable change was determined at least 4.99 degrees. The results are shown in Table 3 and Bland Altman plots are presented in Figure 2. Inter-rater reliability is moderate for the right foot (ICC $=0.73,95 \% \mathrm{CI}: 0.52-0.86)$ and slightly poorer for the left foot (ICC $=0.65,95 \%$ CI: $0.39-0.81$ ). SEM was slightly larger than within intra-rater reliability and topped at 2.34 degrees. The smallest detectable change in this group of subjects was determined to be at least 5 degrees. The concurrent validity of the Spirit Level Plus application is excellent, indicated by an ICC $>0.999$, with $95 \%$ confidence interval of [0. 999822, 0. 9999622]. The Bland Altman plot for concurrent validity is presented in Figure 3.

\section{Discussion}

The intra-rater and inter-rater reliability of the weight-bearing ankle dorsiflexion ROM measurement was moderate to good with ICC ranging from 0.65 to 0.85 . The results are comparable to the results of Gosse et al. (2021), who determined moderate to excellent reliability of the mobile goniometer application iPhone level, with ICC ranging from 0.68 to 0.90 . However, the results are only partially comparable to the results of Williams et al. (2013), who used mobile goniometer application TiltMeter App on an Apple iPhone and have reported good reliability (ICC 0.8 or more). There are several possible explanations for why their reliability is higher and the most obvious one is that Williams et al. (2013) were using a different mobile goniometer application on a different type of device with a different operating system (Android versus iOS). Differences in measurements could also be influenced by the application itself. Applications and their specific software platforms need to be properly validated, and any available new version of the application should be re-validated (Mobile medical applications Guidance for industry and food and drug administration staff, 2013). The concurrent validity of the Spirit Level Plus application is excellent $>0.999$, with $95 \%$ confidence interval of [0. 999822, 0. 9999622]. Bland-Altman plot (Figure 3) shows a tendency to larger measured angles with the Spirit Level Plus application. The tilt is larger with the large angle, however it stays within 1 degree. Mean difference between the two methods is 0.3 degrees with $95 \%$ confidence interval of $[-0.28,0.88]$.

Additionally, there were some differences in the measurement procedures used in the present study as compared to Williams et al. (2013). While Williams et al. (2013) measured only the right ankle, we measured both ankles. The left was measured from the participant's left side, and 
199

200

201

202

203

204

205

206

207

208

209

210

211

212

213

214

215

216

217

218

219

220

221

222

223

224

225

226

227

228

229

230

231

232

233

234

235

236

237

238

the right one from the right side, so the examiner's dominant hand didn't always have the same function. This could explain the differences in the ICC between left and right side in our subjects.

Inter-rater reliability might be lower in the present study due to the inexperience of the physiotherapy student. A novice rater that participated in the study of Williams et al. (2013), already had 2 years of clinical experience and had routinely used the weightbearing ankle dorsiflexion ROM measurement technique during clinical examinations as well as the experienced rater. Interestingly, the intra-rater reliability of a clinician in training and a novice rater was higher (ICC 0.90) when using the iPhone app then the intra-rater reliability of an experienced clinician (ICC 0.75) (Gosse et al., 2021).

It has been suggested that, rather than calibrating the device on the floor, it might be more appropriate to calibrate the device when it is placed on the Achilles tendon while the subject is standing in a neutral starting position. By doing so we would measure the actual range of motion. Another suggestion was, that it might be more suitable to use the longer side of the smartphone, rather than the short one, but because of the different calf shapes we doubt that this argument has much validity. Another limitation of this study was that participants were not gender balanced.

In general, the limitation of the weight-bearing ankle dorsiflexion ROM measurements is that it cannot be used when weight-bearing is contraindicated (Bennell et al., 1998; Konor et al., 2012; Rabin \& Kozol, 2012). The procedure is less objective than the non-weight-bearing passive one, because the subject is the one that determines the end position. On that account the examiner also loses important information about the end feel of the movement (Zunko \& Puh, 2016).On the other hand, the procedure is fast, simple and is more suitable to assess functional ankle dorsiflexion ROM (Konor et al., 2012; Rabin \& Kozol, 2012; O’Shea \& Grafton, 2013). Unlike passive non-weight-bearing measurement of ankle dorsiflexion ROM it can easily be performed by one examiner only, which is an important advantage for the examiners that must perform the measurements alone due to different circumstances (Palmer \& Epler, 1990; Jakovljević \& Hlebš, 2011).

One advantage of using mobile application rather than the universal goniometer, is that determining the axis of rotation is not necessary. This also applies to the digital and gravity goniometers. Konor et al. (2012) simplified weight-bearing ankle dorsiflexion ROM measurement using the universal goniometer by aligning the stable branch of the goniometer with the floor and not the fifth metatarsal like Dickson et al. (2012).

Rabin and Kozol (2012) recommend choosing the measurement method according to the aim of the measurement. If the aim is to primarily assess individual's functioning (walking, stair climbing, squatting etc.), the weight-bearing method is more appropriate. By choosing this

Peer] reviewing PDF | (2021:03:58796:2:0:CHECK 19 Jul 2021) 
239

240

241

242

243

244

245

246

247

248

249

250

251

252

253

254

255

256

257

258

259

260

261

262

263

264

265

266

267

268

269

270

271

272

273

274

275

276

277

278

method, we can also avoid false negative results, since in some individuals the difference in ankle dorsiflexion ROM between the affected and the non-affected side is only detectable in weight-bearing position (Jones et al., 2005). The correlation between weight-bearing ankle dorsiflexion ROM and non-weight-bearing ADROM is only moderate due to 3 to 4 times higher forces affecting the joints of the foot during standing (Jones et al., 2005; Krause et al., 2011).

Differences in measuring procedures could also affect the results of the measurements (Krause et al., 2011; Rabin \& Kozol, 2012). Examiners used various measuring tools for the weight-bearing ankle dorsiflexion ROM measurements (universal classical goniometer, liquid or digital gravity goniometer, mobile applications of goniometers, centimetre measuring tape, ruler or special devices), some performed measurements on the front, some on the rear leg, with the knee flexed or extended.

Those who used a gravity goniometer or a mobile goniometer application measured the tibial inclination on different locations (superior to the posterior calcaneal tuberosity (Dickson et al., 2012; Williams, Caserta \& Haines, 2013, Banwell et al., 2019; Goose et al., 2021), on the lateral (Cejudo et al., 2014) or anterior (Bennell et al., 1998; Dickson et al., 2012; Vohralik et al., 2015) part of the tibia, at different heights). Those who used a universal classical goniometer placed the fixed arm parallel to the fifth metatarsal or the ground. Dickson et al. (2012) suggested liquid gravity goniometer, placed superior to the posterior calcaneal tuberosity, as the most appropriate measurement tool for the weight-bearing ankle dorsiflexion ROM measurement. Several authors used digital gravity goniometer (Munteanu et al., 2009; Krause et al., 2011; Evans, Rome \& Peet, 2012; Konor et al., 2012; Williams, Caserta \& Haines, 2013; Banwell et al., 2019; Goose et al., 2021). Mobile goniometer applications, based on built-in sensors, have similar features as digital and liquid gravity goniometers (Williams, Caserta \& Haines, 2013; Vohralik et al., 2015). Affordability is one of the advantages of mobile applications, as many of them are cost-free. Williams et al. (2013) used Tiltmeter; a mobile application installed on an IOS smartphone in their study, but there are many applications available that can be used on Android smartphones as well (Mourcou et al., 2015). In our study we used the application Spirit Level Plus on an Android Huawei P8lite smartphone, indicating at least moderate reliability.

Minimal detectable change in our study was higher $\left(5.0^{\circ}-6.5^{\circ}\right)$ as compared to the results of Williams et al. (2013) $\left(2.2^{\circ}-4.4^{\circ}\right)$, Gosse et al. (2021) $\left(2.10^{\circ}-5.7^{\circ}\right)$ and Banwell et al. (2019) $\left(2.4^{\circ}-5.0^{\circ}\right)$ In the studies where universal classical goniometer was used to measure ankle dorsiflexion ROM in weight-bearing position (Konor et al., 2012; Dickson et al., 2012), minimal detectable change was $5^{\circ}$ to $7.7^{\circ}$, which does not deviate significantly from our results, neither is the difference clinically significant. Literature review, conducted by Zunko and Puh (2016), revealed that minimal detectable change was smallest in studies where they used liquid gravity goniometers $\left(1.5^{\circ}-3.9^{\circ}\right)$ (Bennell et al., 1998; Dickson et al., 2012; Cejudo et al., 2014) or mobile goniometer applications $\left(2.2^{\circ}-5.2^{\circ}\right)$ (Williams, Caserta \& Haines, 2013). In the study by 
279 Konor et al (2012), Cejudo et al (2014) and our study, reliability was evaluated for both legs, 280 while in the study by Williams et al (2013) reliability was performed only for the right leg and in 281 study by Dickson et al (2021) and Bennell et al (1998) reliability was performed only for the left 282 leg.

283

284

285

286

287

288

289

290

291

292

293

294

295

296

297

298

299

300

301

302

303

304

305

306

307

308

309

310

311

312

313

314

315

316

\section{Conclusions}

Inter-rater and intra-rater reliability of the weight-bearing ankle dorsiflexion ROM measurement, using a mobile goniometer application Spirit Level Plus installed on an Android smartphone is moderate. The concurrent validity of the Spirit Level Plus application is excellent. Further work is required to determine the normative values of ankle dorsiflexion ROM and to determine the differences in ankle dorsiflexion ROM among different age groups and gender, before its recommendation in clinical settings.

\section{Acknowledgements}

We thank the physiotherapy student for their work as a second examiner and to all the participants for their cooperation. The authors acknowledge the financial support from the Slovenian Research Agency (research core funding no. P3-0388).

\section{References}

Akeson WH, Amiel D, Abel MF, Garfin SR, Woo SL. 1987. Effects of immobilization on joints. Clinical Orthopaedics and Related Research:28-37.

Banwell HA, Uden H, Marshall N, Altmann C, Williams CM. 2019. The iPhone Measure app level function as a measuring device for the weight bearing lunge test in adults: a reliability study. Journal of foot and ankle research 12:1-7.

Barg A, Pagenstert GI, Hügle T, Gloyer M, Wiewiorski M, Henninger HB, Valderrabano V. 2013. Ankle osteoarthritis: etiology, diagnostics, and classification. Foot and Ankle Clinics 18:411-426. DOI: 10.1016/j.fcl.2013.06.001.

Bennell K, Khan KM, Matthews B, De Gruyter M, Cook E, Holzer K, Wark JD. 1999. Hip and ankle range of motion and hip muscle strength in young female ballet dancers and controls. British journal of sports medicine 33:340-346.

Bennell KL, Talbot RC, Wajswelner H, Techovanich W, Kelly DH, Hall AJ. 1998. Intra-rater and inter-rater reliability of a weight-bearing lunge measure of ankle dorsiflexion. The Australian Journal of Physiotherapy 44:175-180. DOI: 10.1016/s0004-9514(14)60377-9. Bohannon RW, Tiberio D, Zito MA. 1997. Improving ankle dorsiflexion. Physical therapy 77:982-983.

Burns J, Crosbie J. 2005. Weight bearing ankle dorsiflexion range of motion in idiopathic pes cavus compared to normal and pes planus feet. The Foot 15:91-94. DOI: 10.1016/j.foot.2005.03.003. 
317 Cejudo A, Sainz de Baranda P, Ayala F, Santonja F. 2014. A simplified version of the weight318 bearing ankle lunge test: description and test-retest reliability. Manual Therapy 19:355-359. 319 DOI: $10.1016 /$ j.math.2014.03.008.

320 Charles J, Scutter SD, Buckley J. 2010. Static ankle joint equinus: toward a standard definition 321 and diagnosis. Journal of the American Podiatric Medical Association 100:195-203. DOI:

$32210.7547 / 1000195$.

323 Cheung JT-M, Zhang M, An K-N. 2006. Effect of Achilles tendon loading on plantar fascia 324 tension in the standing foot. Clinical Biomechanics (Bristol, Avon) 21:194-203. DOI:

325 10.1016/j.clinbiomech.2005.09.016.

326 Chung SG, Van Rey E, Bai Z, Roth EJ, Zhang L-Q. 2004. Biomechanic changes in passive 327 properties of hemiplegic ankles with spastic hypertonia. Archives of Physical Medicine and 328 Rehabilitation 85:1638-1646. DOI: 10.1016/j.apmr.2003.11.041.

329 Dickson D, Hollman-Gage K, Ojofeitimi S, Bronner S. 2012. Comparison of Functional Ankle 330 Motion Measures in Modern Dancers. Journal of Dance Medicine \& Science: Official 331 Publication of the International Association for Dance Medicine \& Science 16:116-125. 332 Dinh NV, Freeman H, Granger J, Wong S, Johanson M. 2011. Calf stretching in non-weight 333 bearing versus weight bearing. International Journal of Sports Medicine 32:205-210. DOI: 334 10.1055/s-0030-1268505.

335 Duthon VB, Lübbeke A, Duc SR, Stern R, Assal M. 2011. Noninsertional Achilles tendinopathy 336 treated with gastrocnemius lengthening. Foot \& Ankle International 32:375-379. DOI:

337 10.3113/FAI.2011.0375.

338 Evans AM, Rome K, Peet L. 2012. The foot posture index, ankle lunge test, Beighton scale and 339 the lower limb assessment score in healthy children: a reliability study. Journal of Foot and 340 Ankle Research 5:1. DOI: 10.1186/1757-1146-5-1.

341 Franko OI, Tirrell TF. 2012. Smartphone app use among medical providers in ACGME training 342 programs. Journal of medical systems 36:3135-3139.

343 Gajdosik RL, Vander Linden DW, Williams AK. 1999. Influence of age on length and passive 344 elastic stiffness characteristics of the calf muscle-tendon unit of women. Physical Therapy 345 79:827-838.

346 Garrick JG, Requa RK. 1988. The epidemiology of foot and ankle injuries in sports. Clinics in 347 Sports Medicine 7:29-36.

348 Gehlsen GM, Whaley MH. 1990. Falls in the elderly: Part II, Balance, strength, and flexibility. 349 Archives of Physical Medicine and Rehabilitation 71:739-741.

350 Gosse G, Ward E, McIntyre A, Banwell HA. 2021. The reliability and validity of the weight351 bearing lunge test in a Congenital Talipes Equinovarus population (CTEV). PeerJ 9:e10253.

352 DOI: $10.7717 /$ peerj.10253.

353 Jakovljević M, Hlebš S. 2011. Meritve gibljivosti sklepov, obsegov in dolţin udov. 2. dop. izd.

354 Ljubljana: Univerza $v$ Ljubljani Zdravstvena fakulteta. 
355 Jones R, Carter J, Moore P, Wills A. 2005. A study to determine the reliability of an ankle

356

357

358

359

360

361

362

363

364

365

366

367

368

369

370

371

372

373

374

375

376

377

378

379

380

381

382

383

384

385

386

387

388

389

390

391

392

393

dorsiflexion weight-bearing device. Physiotherapy 91:242-249. DOI:

10.1016/j.physio.2005.04.005.

Kluding PM, Santos M. 2008. Effects of ankle joint mobilizations in adults poststroke: a pilot study. Archives of physical medicine and rehabilitation 89:449-456.

Konor MM, Morton S, Eckerson JM, Grindstaff TL. 2012. Reliability of three measures of ankle dorsiflexion range of motion. International Journal of Sports Physical Therapy 7:279-287.

Krause DA, Cloud BA, Forster LA, Schrank JA, Hollman JH. 2011. Measurement of ankle dorsiflexion: a comparison of active and passive techniques in multiple positions. Journal of Sport Rehabilitation 20:333-344. DOI: 10.1123/jsr.20.3.333.

Mobile medical applications - Guidance for industry and food and drug administration staff (2013). http://www.fda.gov/downloads/MedicalDevices/.../UCM263366.pdf. <4. 1. 2018>.

Morales CR, Lobo CC, Sanz DR, Corbalán IS, Ruiz BR, López DL. 2017. The concurrent validity and reliability of the Leg Motion system for measuring ankle dorsiflexion range of motion in older adults. PeerJ 5:e2820.

Mourcou Q, Fleury A, Diot B, Franco C, Vuillerme N. 2015. Mobile phone-based joint angle measurement for functional assessment and rehabilitation of proprioception. BioMed research international 2015.

Munteanu SE, Strawhorn AB, Landorf KB, Bird AR, Murley GS. 2009. A weightbearing technique for the measurement of ankle joint dorsiflexion with the knee extended is reliable.

Journal of Science and Medicine in Sport 12:54-59. DOI: 10.1016/j.jsams.2007.06.009.

O'Shea S, Grafton K. 2013. The intra and inter-rater reliability of a modified weight-bearing lunge measure of ankle dorsiflexion. Manual Therapy 18:264-268. DOI:

10.1016/j.math.2012.08.007.

Palmer ML, Epler ME. 1990. Clinical assessment procedures in physical therapy. Lippincott Williams \& Wilkins.

Portney LG, Watkins MP, others. 2009. Foundations of clinical research: applications to practice. Pearson/Prentice Hall Upper Saddle River, NJ.

Powden CJ, Hoch JM, Hoch MC. 2015. Reliability and minimal detectable change of the weightbearing lunge test: A systematic review. Manual Therapy 20:524-532. DOI: 10.1016/j.math.2015.01.004.

R Core Team (2013). R: A language and environment for statistical computing. R Foundation for Statistical Computing, Vienna, Austria.

Rabin A, Kozol Z. 2012. Weightbearing and nonweightbearing ankle dorsiflexion range of motion: are we measuring the same thing? Journal of the American Podiatric Medical Association 102:406-411. DOI: 10.7547/1020406.

Rabin A, Kozol Z, Spitzer E, Finestone AS. 2015. Weight-bearing ankle dorsiflexion range of motion-can side-to-side symmetry be assumed? Journal of Athletic Training 50:30-35. DOI:

10.4085/1062-6050-49.3.40.

Peer) reviewing PDF | (2021:03:58796:2:0:CHECK 19 Jul 2021) 
394 Rose KJ, Burns J, North KN. 2010. Factors associated with foot and ankle strength in healthy 395 preschool-age children and age-matched cases of Charcot-Marie-Tooth disease type 1A. Journal 396 of child neurology 25:463-468.

397 Searle MOsteo A, Spink MJ, Chuter VH. 2018. Validation of a weight bearing ankle equinus

398 value in older adults with diabetes. Journal of Foot and Ankle Research 11:62. DOI:

399 10.1186/s13047-018-0306-x.

400 Vohralik SL, Bowen AR, Burns J, Hiller CE, Nightingale EJ. 2015. Reliability and validity of a 401 smartphone app to measure joint range. American Journal of Physical Medicine \& Rehabilitation 402 94:325-330. DOI: 10.1097/PHM.0000000000000221.

403 Watson C, Boland R, Refshauge K. 2008. Measurement Reliability of Swelling in the Acute 404 Ankle Sprain. The Foot \& Ankle Journal 1. DOI: 10.3827/faoj.2008.0112.0004.

405 Wilken J, Rao S, Estin M, Saltzman CL, Yack HJ. 2011. A new device for assessing ankle 406 dorsiflexion motion: reliability and validity. The Journal of Orthopaedic and Sports Physical 407 Therapy 41:274-280. DOI: 10.2519/jospt.2011.3397.

408 Williams CM, Caserta AJ, Haines TP. 2013. The TiltMeter app is a novel and accurate 409 measurement tool for the weight bearing lunge test. Journal of Science and Medicine in Sport 410 16:392-395. DOI: 10.1016/j.jsams.2013.02.001.

411 Young R, Nix S, Wholohan A, Bradhurst R, Reed L. 2013. Interventions for increasing ankle 412 joint dorsiflexion: a systematic review and meta-analysis. Journal of foot and ankle research $4136: 1-10$.

414 Zunko H, Puh U. 2016. Zanesljivost merjenja obsega gibljivosti skočnega sklepa v stoječem 415 položaju-pregled literature. Fizioterapija 24:25-33.

416 


\section{Figure 1}

Weight-bearing ankle dorsiflexion range of motion measurement

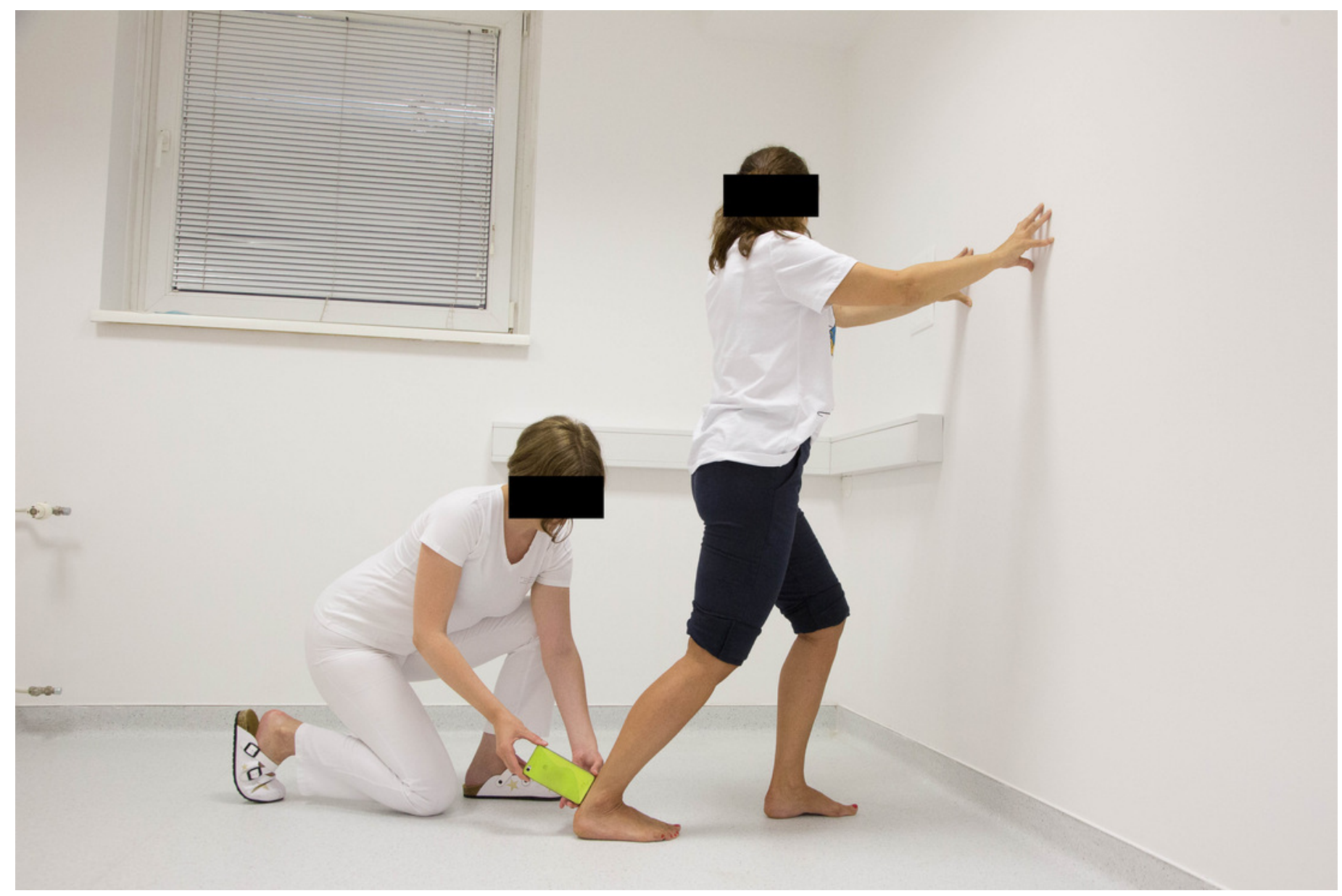


Figure 2

\section{Bland Altman plots}
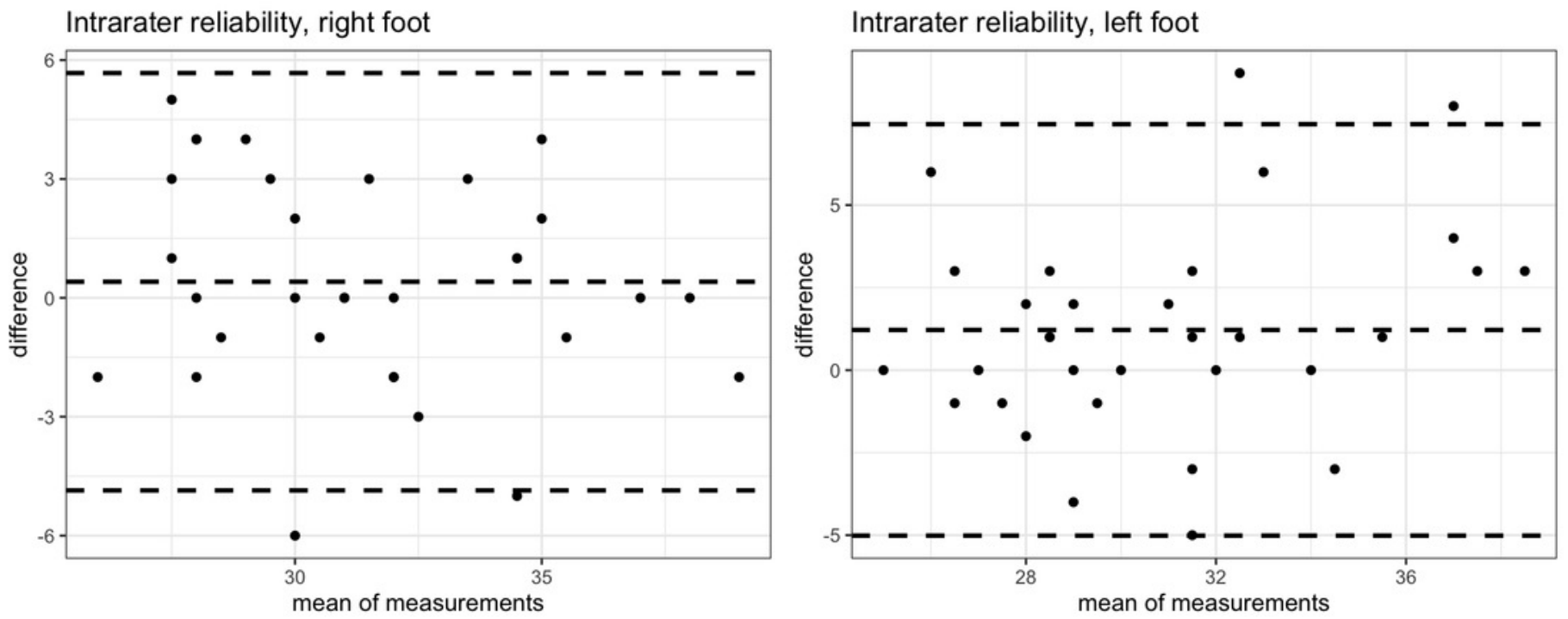

Interarater reliability, right foot

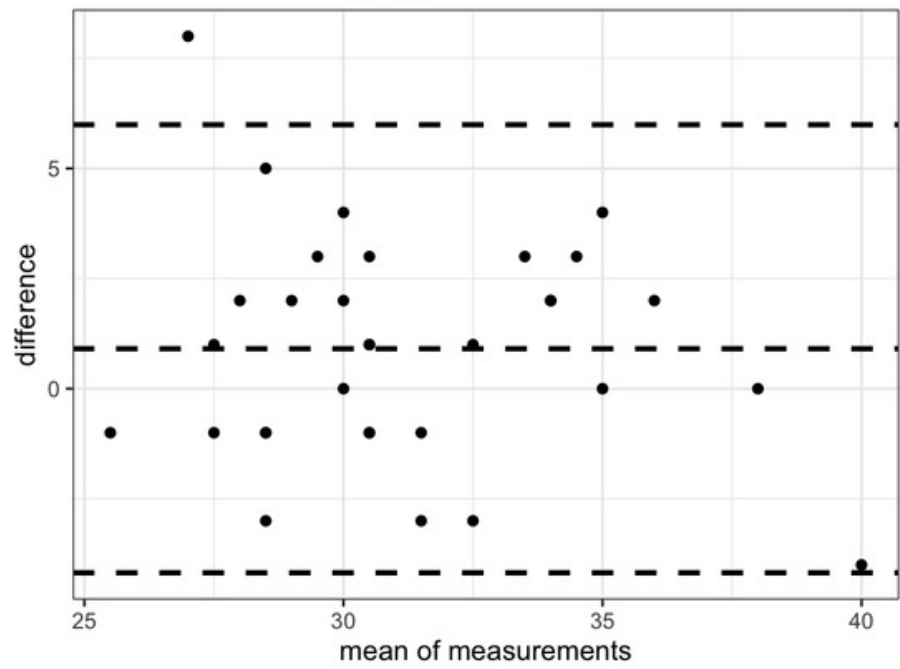

Interarater reliability, left foot

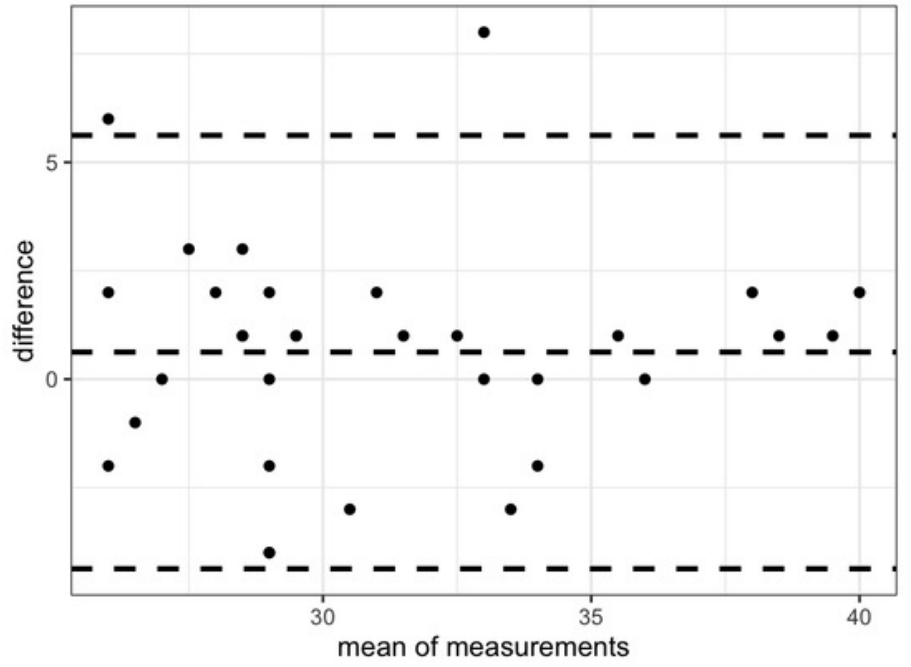


Figure 3

Bland-Altman plot of the concurrent validity

\section{Concurrent validity}

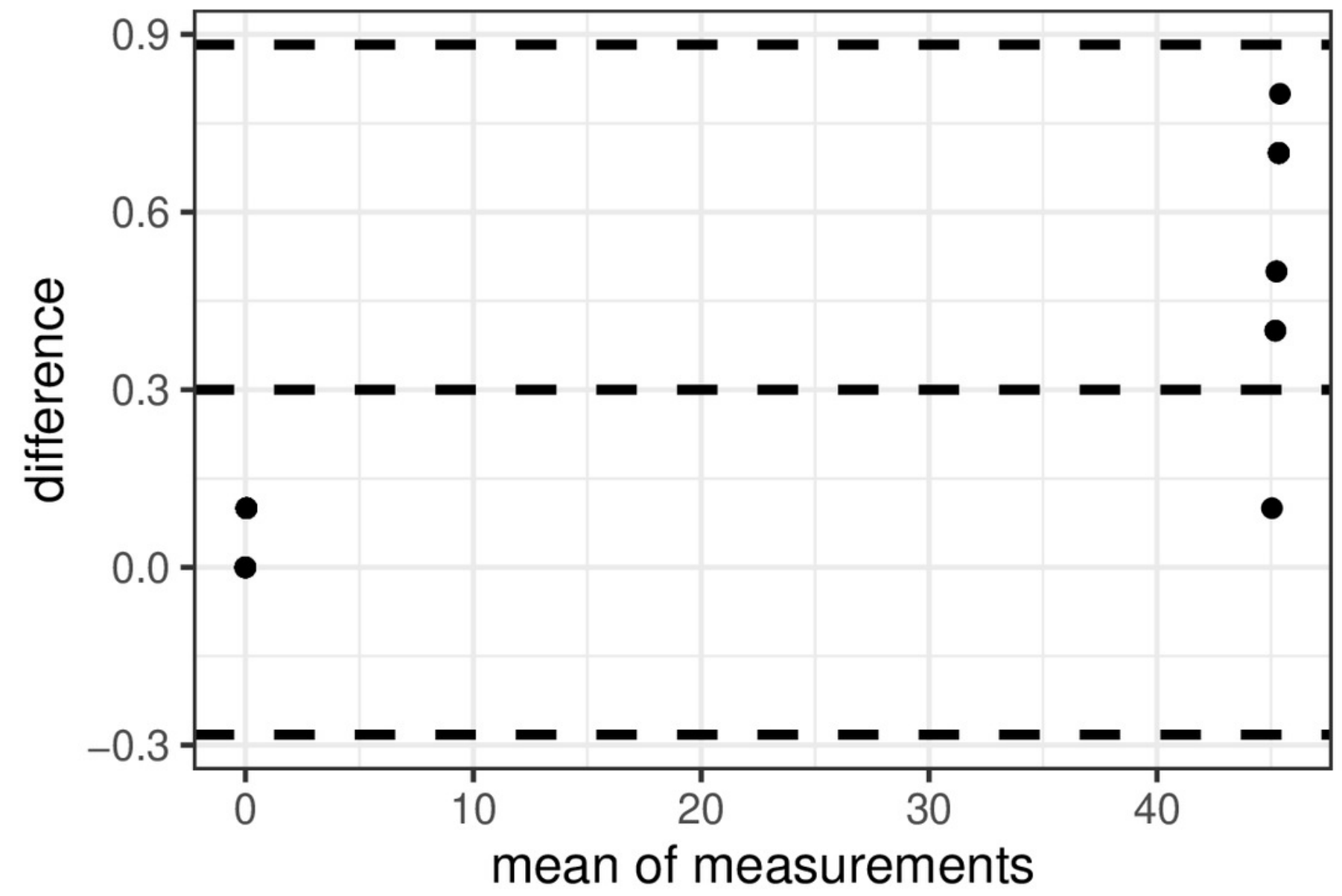


Table $\mathbf{1}$ (on next page)

Descriptive statistics of the participants 
1 Table 1 Descriptive statistics of the participants.

\begin{tabular}{lccc}
\hline & $\begin{array}{c}\text { Age } \\
\text { (years) }\end{array}$ & $\begin{array}{c}\text { Height } \\
\text { (cm) }\end{array}$ & $\begin{array}{c}\text { Body mass } \\
\text { (kg) }\end{array}$ \\
\hline Mean & 20.9 & 170.7 & 66.2 \\
Median & 21 & 169.5 & 64 \\
Standard Deviation & 1.7 & 8.1 & 11.6 \\
Range & $19-27$ & $155-187$ & $50-95$ \\
\hline
\end{tabular}

2 
Table 2 (on next page)

Ankle dorsiflexion range of motion measurements 
1 Table 2 Ankle dorsiflexion range of motion measurements.

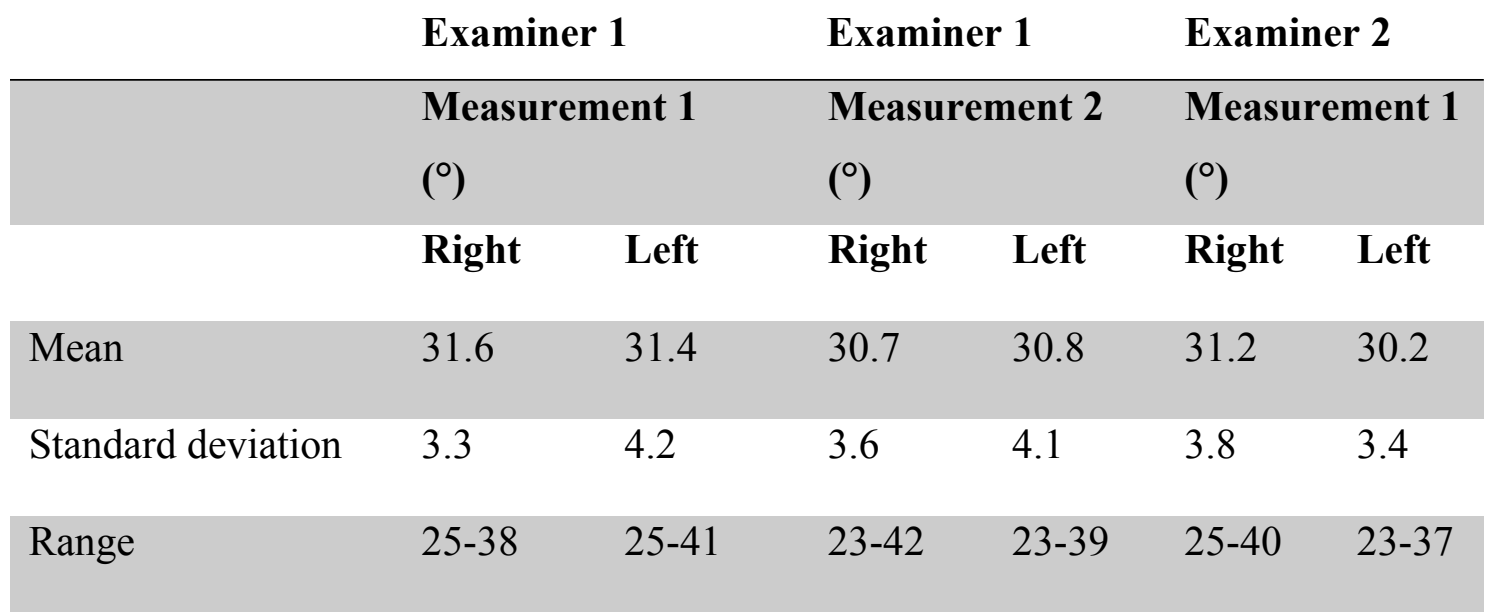


Table 3(on next page)

Intra-rater and inter-rater reliability

Notes. Abbreviations: ICC, intraclass correlation coefficient; $\mathbf{C l}$, confidence interval; SEM, standard error of measurement; MDC, minimum detectable change (based on $95 \% \mathrm{Cl}$ ). 
1 Table 3 Intra-rater and inter-rater reliability.

2 Intra-rater reliability

\begin{tabular}{lllll}
\hline & ICC & $\mathbf{9 5 \%}$ IC & SEM & MDC \\
\hline Right & 0.72 & $0.49-0.85$ & 1.89 & 5.24 \\
Left & 0.82 & $0.66-0.91$ & 1.80 & 4.99 \\
\hline
\end{tabular}

3 Inter-rater reliability

\begin{tabular}{lllll}
\hline & ICC & $\mathbf{9 5 \%}$ IC & SEM & MDC \\
\hline Right & 0.73 & $0.52-0.86$ & 1.89 & 5.23 \\
Left & 0.65 & $0.39-0.81$ & 2.34 & 6.49
\end{tabular}

4 Notes.

5 Abbreviantions: ICC, intraclass correlation coefficient; $\mathbf{C I}$, confidence interval; SEM, standard error of measurement;

$6 S E M=S D \times \sqrt{1-I C C} ;$ MDC, minimum detectable change (based on 95\% CI);MDC $=1,96 \times S E M \times \sqrt{2}$.

7

8 